\title{
Obstetric and Neonatal Outcome in Second- Pregnancy Patients with One Prior Cesarean Section at A Costarican Hospital 2006-2007
}

\author{
Manrique Leal-Mateos, Loretta Giacomin-Carmiol, Rafael Angel \\ Moya-Sibaja
}

Obstetric Department, Hospital Calderón Guardia.

Abbreviations: CCSS, Caja

Costarricense de Seguro Social;

HCG, Dr. Rafael Ángel Calderón

Guardia.

E-mail:

Manrique Leal Mateos

E-mail: manrique.leal@gmail.com

\section{Abstract}

Aim: To analyze neonatal and obstetric outcomes in second-pregnancy patients with 1 prior cesarean section.

Materials and methods: This study is a cross-sectional observational study. We analyzed 306 medical records of patients treated at the Dr. Rafael A. Calderón Guardia Hospital (HCG), from January 1st 2006 to December 31 st of 2007. Maternal variables associated to prenatal control were age and obstetrical indication of the previous cesarean delivery. Variables associated to delivery were gestational age, type of delivery, obstetric complications, and length of hospital stay. The neonatal variables were weight at birth, 5 minute Apgar score, neonatal complications, need for neonatal resuscitation or newborn hospitalization and length of hospital stay.

Results: 59, $1 \%$ of the patients with 1 prior cesarean section had successful vaginal delivery. The percentage of maternal complications was significantly higher for those who underwent a cesarean section during labor.

Uterine rupture occurred in 1,3\% of the cases and no maternal or neonatal deaths were found as a consequence of such complication. The percentage of neonatal complications was similar for both groups. The need for neonatal resuscitation was significantly higher in the group that underwent an elective caesarean delivery.

Conclusion: Our results show that at the HCG from January 1st 2006 to December 31 st of 2007, a vaginal delivery in second-pregnancy patients with 1 prior caesarean delivery appears to be safe. The percentage of successful vaginal deliveries, obstetric complications and uterine rupture were similar to those reported in international literature.

Recibido: $7^{\text {th }}$ of August 2009 Aceptado: $10^{\text {th }}$ November, 2009 
Vaginal delivery after a cesarean section has increased in the last 20 years. The risks, benefits and security of this procedure have been of interest in the last decade. ${ }^{1,2}$

The success of this procedure is reported to be $60-80 \%$. Some of the reasons that the obstetrician should consider to recommend a vaginal delivery in a patient with a previous cesarean section are: less hospitalization time, less incidence of bleeding after the delivery and less incidence of puerperal infections. Nevertheless, there is a habit to perform a second elective cesarean section in patients with this history, even though there are good reported results found in the international literature.

The complications of this procedure are infrequent it is very important to consider the clinical importance for the mother and product due to its high morbidity and mortality.

There are some factors that can help to select the candidates for a delivery test and increase the percentage of success. These same factors can contribute to avoid vaginal delivery in some patients and decrease the possible complications derived from this procedure.

In the hospital, there is no clinical evidence about the neonatal and obstetrical results of patients with history of a prior cesarean sections who are submitted to a delivery test in the next pregnancy. So, the present study has as aim to analyze the obstetrical and neonatal results of patients with their second pregnancy that had a prior cesarean section, whose delivery was done at the Obstetrics Department at the Hospital Dr. Rafael A. Calderón Guardia (HCG).

\section{Materials and Methods}

An observational, analytic, transversal cohort study was done to achieve the objectives. The research has approval of the hospital's Investigational Research Board (Office CLOBIHCG-33-06-08).

Using a non-probabilistic sampling the medical historiesof pregnant woman with prior cesarean section, which visited the Obstetrics Department of the HCG, from January $1^{\text {st }}, 2007$ to December $31^{\text {st }}, 2007$. Revising the delivery register where all deliveries are routinely registered identified the cases.
Restrictive criteria were used to select the sample, with the purpose to obtain homogenous study groups and to reduce the presence of variables that could influence the analysis of obstetrical and neonatal results of patients with prior cesarean sections that were submitted to a delivery test.

Inclusion criteria were pregnant women over 18 years of age, but younger than 35 years, with a gestational age over 37 weeks, with a second pregnancy, with only one product and cephalic.

Exclusion criteria were every patient with placenta praevia, history of classic cesarean section, uterine surgery with myomectomy, products that weight less than 2500 grams or more than 4000 grams, no part of the attraction area of $\mathrm{HCG}$, or that did not meet all the inclusion criteria. The data collection was done using an electronic document designed for the study.

The maternal variables related with the prenatal control that were included were: age in years and obstetrical indication that motivated the prior cesarean section.

The variables related to the delivery that were analyzed were: gestational age in weeks, type of delivery, obstetrical complications due to labor and hospitalizations days.

The neonatal variables that were studied were: weight at birth in kilograms, Apgar score at 5 minutes, neonatal complications due to labor, need of neonatal resuscitation and need to hospitalize the newborn, and days of hospitalizations when it corresponds.

EpiInfo 2002 was the program used to process the data. The qualitative variables were analyzed using frequencies and proportions. The results derived form the quantitative values were expressed as measure of central tendency and dispersion. The relation between qualitative variables was done using chi test $\left(\mathrm{X}^{2}\right)$. The difference between averages and proportions was compared using ANOVA. The Fisher exact test and Kruskal-Wallis were required. The level of significance was dictated to be $\mathrm{p} \leq$ 0.05. Excell 2007 was used to make tables. 


\section{Results}

Of the 344 patients that that fulfilled the inclusion criteria, there was necessary to exclude 2 because of placenta praevia, 10 for product weight less than 2500 grams and 26 for more producto weight more than 4000 grams.

Out of the 306 patients studied, the average age was 27.1 years old $(\mathrm{SD}+4.1)$. The most frequent diagnosis that explained the prior cesarean section was cephalodesproportion pelvis, with 79 cases $(25.8 \%$, IC $95 \%$ 21.1-31-2), followed by delayed labor with 52 cases $(17.0 \%$, IC 95\% 13.1-21.8) and pelvic presentation with 48 cases $(15.7 \%$, IC $95 \% 11.9-20.4)$. The average gestational age was 38.9 weeks $(\mathrm{SD} \pm 1.4)$.

The 51.3\% ( $\mathrm{n}=157$, IC 95\% 45.657.0) of the patients were programmed an elective cesarean section during the prenatal control or this procedure was done during the onset of labor. Of the group, the most frequent indication for the second cesarean section was the fact that they had a prior cesarean section $(n=109$ cases; 69.4\%, IC 95\% 61.6-76.5).

The $48.7 \% \quad(n=149$; IC $95 \% 43.0$ 54.4) of the remaining patients were submitted to a labor test at the moment they were admitted to the hospital. OF this group, the $59.1 \% \quad(\mathrm{n}=88 ;$ IC $95 \%$ 50.7-67.0 $)$ had a successful vaginal delivery and in $40.9 \%$ ( $n=61$; IC 95\% 33.0-49.3) had an intrapartum cesarean section. Of this last group, the most frequent indication for the second cesarean section was delayed labor with 20 cases (32.8\%; IC 95\% 21.3-48.0).

The variables related with the labor are shown on Table 1. In general, 28 obstetrical complications were registered $(9.2 \%$; IC $95 \% 6.3-13.1)$. Out of the complications, the most frequent between the groups were trans-surgical bleeding, with a total of 15 cases $(53.6 \%$; IC $95 \% 33.9-72.5)$, followed by intrapartum bleeding with 6 cases (21.4\%; IC 95\% 8.3-41.0) and postpartum bleeding with 5 cases $(17.9 \%$; IC 95\% 6.1 36.9). The percentage of complications was significantly higher in the group of patients where an intrapartum cesarean section was performed. No case of placenta accreta was reported in any of the groups. In average, the patients that had a successful vaginal delivery had a minor in-hospital stay.
Table 1: Maternal characteristics al the labor, study on the obstetrical and neonatal outcomes of patients with prior cesarean section, HCG, 2006-2007

\begin{tabular}{|l|l|l|l|l|}
\hline & $\begin{array}{l}\text { Vaginal } \\
\text { Delivery } \\
\mathbf{n = 8 8}\end{array}$ & $\begin{array}{l}\text { Intrapartum } \\
\text { Cesarean } \\
\text { Section } \\
\mathbf{n = 6 1}\end{array}$ & $\begin{array}{l}\text { Elective } \\
\text { Cesarean } \\
\text { Section } \\
\mathbf{n = 1 5 7}\end{array}$ & $\begin{array}{l}\text { V } \\
\text { Value }\end{array}$ \\
\hline $\begin{array}{l}\text { Maternal age } \\
\text { (years) }\end{array}$ & 26.3 & 25.6 & 28.1 & $<0.05$ \\
\hline $\begin{array}{l}\text { Gestational } \\
\text { age (weeks) }\end{array}$ & 39.1 & 39.2 & 38.8 & 0.07 \\
\hline $\begin{array}{l}\text { Obstetrical } \\
\text { complications } \\
\text { (\%) }\end{array}$ & 5.7 & 18.0 & 7.6 & 0.02 \\
\hline $\begin{array}{l}\text { Inpatient stay } \\
\text { (average } \\
\text { days) }\end{array}$ & 1.3 & 2.2 & 2.2 & $<0.05$ \\
\hline $\begin{array}{l}\text { Maternal } \\
\text { deaths }\end{array}$ & 0 & 0 & 0 & - \\
\hline
\end{tabular}

Uterine rupture was present in $1.3 \%$ $(n=2$; IC 95\% 0.2-4.8) of the cases that were submitted to labor test. These patients had a cesarean section because of acute fetal distress. No mother or product died due to this complication.

The variables related to the newborn are shown in Table 2. As it shows, the percentage of an Apgar score at 5 minutes less than 7 ,was significantly higer in the products of mothers submitted to a labor test and ended it by a cesarean section. The products with Apgar score lower than 7 at 5 minutes were those born from mothers who had an uterine rupture during the delivery.

The need of neonatal resuscitation was significantly higher in the products of mothers whose products had an elective cesarean section. Out of the 6 complications found, 4 of them were neonatal distress syndrome, and all of these presented in the group that had an elective cesarean section. 


\begin{tabular}{|c|c|c|c|c|}
\hline \multicolumn{5}{|c|}{$\begin{array}{l}\text { Table 2: Neonatal characteristics, study on the } \\
\text { obstetrical and neonatal outcomes of patients } \\
\text { with prior cesarean section, HCG, 2006-2007 }\end{array}$} \\
\hline & $\begin{array}{l}\text { Vaginal } \\
\text { Delivery } \\
\mathrm{n}=88\end{array}$ & $\begin{array}{l}\text { Intrapartu } \\
\mathrm{m} \\
\text { Cesarean } \\
\text { Section } \\
\mathrm{n}=61\end{array}$ & $\begin{array}{l}\text { Elective } \\
\text { Cesarean } \\
\text { Section } \\
\mathrm{n}=157\end{array}$ & $\begin{array}{l}\mathrm{p} \\
\text { Value }\end{array}$ \\
\hline $\begin{array}{l}\text { Neonatal } \\
\text { weight } \\
\text { (average) }\end{array}$ & 3250.4 & 3281.1 & 3200.3 & 0.27 \\
\hline $\begin{array}{l}\text { Apgar } 5 \\
\min <7(\%)\end{array}$ & 0 & 2.0 & 0 & 0.01 \\
\hline $\begin{array}{l}\text { Neonatal } \\
\text { complicatio } \\
\text { ns }(\%)\end{array}$ & 0 & 3.3 & 2.5 & 0.27 \\
\hline $\begin{array}{l}\text { Resuscitati } \\
\text { on }(\%)\end{array}$ & 2.3 & 4.9 & 10.8 & 0.03 \\
\hline $\begin{array}{l}\text { Hospitalizat } \\
\text { ion }(\%)\end{array}$ & 0 & 3.3 & 1.3 & 0.22 \\
\hline $\begin{array}{l}\text { Inpatient } \\
\text { neonatal } \\
\text { days } \\
\text { (average) }\end{array}$ & 1.2 & 2.2 & 2.2 & $<0.01$ \\
\hline Fetal deaths & 0 & 0 & 0 & - \\
\hline
\end{tabular}

\section{Discussion}

Before commenting the results obtained, it is important to mention some factors that may influence in the data interpretation. First, this study does not measure causality, only the relationship between independent and dependent variables that were selected.

Otherwise, since it is a study based in a hospital, not a populations, the results are applicable only to the patients seen in the HCG. Due to the usage of restrictive selection criteria to select the sample, the results are only applicable to the patients that meet these characteristics. Also, the number of patients was relatively small, so the strength needed to obtain statistical significance is reduced.

Last, since the clinical histories were taken from the patients medical records, the present study is not free of information bias.

Taking into account the facts mentioned before, we it can be concluded that approximately half of the patients with a second pregnancy with a history of prior cesarean section are submitted to labor test at their admission to the HCG. The percentage of successful vaginal delivery is similar to the one reported by the international literature.

It is important to highlight that the percentage of complications was higher in the group of patients that ended the labor test with a cesarean section. Nevertheless, the most frequent complications, like trans-surgical bleeding, cannot be attributed only to the exposition of these patients to a labor test, because there are many factors that influence this complication and the elective cesarean section neither prevents this complication.

The same way, the percentage of uterine in patients submitted to a labor test was similar as the one found in other studies. ${ }^{11,13}$ There were no fatal outcomes due to this complication, it is important to mention that these may be because these type of labor is strictly monitored at our hospital, and this facilitates the immediate detection and the adequate measures are taken to minimize the associated complications the way it is established in international protocols.

Concerning the newborn, it is important to notice that all the newborns with respiratory distress were seen in the group that had an elective cesarean section. Theoretically, it is postulated that the mechanisms involved in the first breath of the newborn may not be present in these products. At the beginning of the labor, the normal expansion and entry of air in the neonatal lung depends on the output of liquid from the fetal lung. This process initiates before birth, but some related factors during labor influence it during this transition. For example, it has been demonstrated that chest compression in the vaginal delivery eliminates liquid from the lungs and facilitates the newborn breathing process. For this reason, children born by cesarean section are not beneficiated by this mechanism, something that may justify the results in the present research. ${ }^{14,15}$

According to the results, it can be concluded that the experience in HCG in the attention of vaginal deliveries after a prior cesarean section seems similar to the data shown in the international literature. Even with the limitations related to statistical strength due to the inclusion criteria, the maternal and neonatal results are similar to other reported studies. 


\section{References}

1. Villar J, Valladares E, Wojdyla D, Zavaleta $\mathrm{N}$, Carroli G, Velazco A et al. Cesarean delivery rates and pregnancy outcomes: The 2005 WHO global survey on maternal and perinatal health in Latin America. The Lancet. 2006; 367:1819-1829.

2. CDC. Vaginal birth after cesarean birthCalifornia 1996-2000. MMWR. 2002; 51: 996998

3. American College of Obstetricians and Gynecologists: Vaginal birth after previous cesarean delivery. ACOG Practice Bulletin No. 54. Washington, DC.: American College of Obstetricians and Gynecologists; 2004.

4. Flamm BL. Once a cesarean, always a controversy. Obstet Gynecol. 1997; 90: 312315 .

5. Coleman V, Erickson K, Schulkin J, Zinberg S, Sachs B. Vaginal birth after cesarean delivery: Practice patterns of Obstetrician-Gynecologits. Obstet Gynecol Survey. 2005; 60: 636-637.

6. Shipp TS. Trial of labor after cesarean: So, What are the risks? Clin Obstet Gynecol. 2004; 47: 365-377.

7. Cahill A, Macones G. Vaginal birth after cesarean delivery: Evidencebased practice. Clin Obstet Gynecol. 2007; 50: 518-525.

8. Mercer BM, Gilbert S, Landon M, Spong CY, Leveno KJ, Rouse DJ et al. Labor outcome with increasing number of prior vaginal births after cesarean delivery. Obstet Gynecol. 2008; 111: 285-291.

9. Flamm BL, Geiger AM. Vaginal birth after cesarean delivery: An admission scoring system. Obstet Gynecol. 1997; 90: 907-910.

10. Gyamfi C, Juhasz G, Gyamfi P, Stone J. Increased success of trial of labor after previous vaginal birth after cesarean. Obstet Gynecol. 2004; 104: 715-719.

11. Landon MB, Hauth JC, Leveno KJ, Spong CY, Leindecker S, Varner MW, et al. Maternal and perinatal outcomes associated with a trial of labor after prior cesarean delivery. N Engl J Med. 2004; 351:2581-9.
12. Chauhan SP, Martin JN, Henrichs CE, Morrison JC, Magann EF. Maternal and perinatal complications with uterine rupture in 142,075 patients who attempted vaginal birth after cesarean delivery: a review of the literature. Am J Obstet Gynecol. 2003; 189:408-17.

13. Macones GA, Peipert J, Nelson DB, Odibo A, Stevens EJ, Stamilio DM, et al. Maternal complications with vaginal birth after cesarean delivery: a multicenter study. Am J Obstet Gynecol. 2005; 193:1656-62.

14. Doherty EG, Eichenwald EC. Cesarean delivery: Emphasis on the neonate. Clin Obstet Gynecol. 2004; 47: 332-341.

15. Roth-Kleiner M, Wagner BP, Bachmann $\mathrm{D}$, Pfenninger J. Respiratory distress syndrome in near-term babies after caesarean section. Swiss Med Wkly. 2003; 133: 283-288.

Translated by: Benjamin Hidalgo 